\title{
Comprehensive two-dimensional gas chromatography with time-of-flight mass spectrometry combined with solid phase microextraction as a powerful tool for quantification of ethyl carbamate in fortified wines. The case study of Madeira wine
}

\author{
Rosa Perestrelo ${ }^{\mathrm{a}, \mathrm{b}}$, Sílvia Petronilho ${ }^{\mathrm{a}}$, José S. Câmara ${ }^{\mathrm{b}}$, Sílvia M. Rocha ${ }^{\mathrm{a}, *}$ \\ a Departamento de Química, Universidade de Aveiro, 3810-193 Aveiro, Portugal

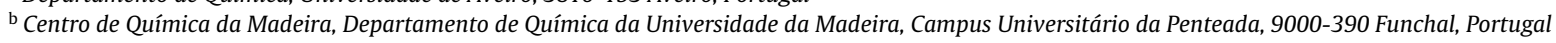

\section{A R T I C L E I N F O}

\section{Article history:}

Received 10 February 2010

Received in revised form 12 March 2010

Accepted 16 March 2010

Available online 24 March 2010

\section{Keywords:}

Ethyl carbamate

Fortified wine

Madeira wine

HS-SPME

$\mathrm{GC} \times \mathrm{GC}-\mathrm{ToFMS}$

\begin{abstract}
A B S T R A C T
An analytical methodology based on headspace solid phase microextraction (HS-SPME) combined with comprehensive two-dimensional gas chromatography-time-of-flight mass spectrometry (GC $\times$ GC-ToFMS) was developed for the identification and quantification of the toxic contaminant ethyl carbamate (EC) directly in fortified wines. The method performance was assessed for dry/medium dry and sweet/medium sweet model wines, and for quantification purposes, calibration plots were performed for both matrices using the ion extraction chromatography (IEC) mode ( $\mathrm{m} / \mathrm{z} 62)$. Good linearity was obtained with a regression coefficient $\left(r^{2}\right)$ higher than 0.981 . A good precision was attained (R.S.D. $<20 \%$ ) and low detection limits (LOD) were achieved for dry $(4.31 \mu \mathrm{g} / \mathrm{L})$ and sweet $(2.75 \mu \mathrm{g} / \mathrm{L})$ model wines. The quantification limits (LOQ) and recovery for dry wines were $14.38 \mu \mathrm{g} / \mathrm{L}$ and $88.6 \%$, whereas for sweet wines were $9.16 \mu \mathrm{g} / \mathrm{L}$ and $99.4 \%$, respectively. The higher performance was attainted with sweet model wine, as increasing of glucose content improves the volatile compound in headspace, and a better linearity, recovery and precision were achieved. The analytical methodology was applied to analyse 20 fortified Madeira wines including different types of wine (dry, medium dry, sweet, and medium sweet) obtained from several harvests in Madeira Island (Portugal). The EC levels ranged from $54.1 \mu \mathrm{g} / \mathrm{L}$ (medium dry) to $162.5 \mu \mathrm{g} / \mathrm{L}$ (medium sweet).
\end{abstract}

(C) 2010 Elsevier B.V. All rights reserved.

\section{Introduction}

Madeira wine is a fortified Portuguese wine made in Madeira Island over the last centuries, and plays an important role in the economy of the Island. The winemaking and ageing processes used for Madeira wines are unique. The fermentation process is stopped by the addition of natural grape spirit in order to obtain an ethanol content of $18-19 \%(\mathrm{v} / \mathrm{v})$. Then, the wine is submitted to a baking process, i.e., the wine is placed in large coated vats and the temperature is slowly increased at about $5^{\circ} \mathrm{C}$ per day and maintained at $45-50^{\circ} \mathrm{C}$ for 3 months. After this treatment, the wine is allowed to undergo a maturation process in oak casks for a minimum of 3 years. Finally, some Madeira wines suffer an ageing process, from minimum of 3-20 years or longer, in cellars at $30-35^{\circ} \mathrm{C}$ by sun influence, and a humidity degree higher than $70 \%$ [1]. Under these conditions, many reactions can occur

\footnotetext{
* Corresponding author. Tel.: +351 234401524; fax: +351 234370084

E-mail addresses: smrocha@ua.pt, scarrico@dq.ua.pt (S.M. Rocha).
}

leading to significant changes in wine, some are crucial to the final remarkable characteristics of Madeira wine, however it may also cause production of ethyl carbamate (EC). According to Stevens and Ough [2], under fairly normal storage temperatures $\left(13-24^{\circ} \mathrm{C}\right)$, and not uncommon concentrations of urea $(1-10 \mathrm{mg} / \mathrm{L})$, a significant amount of EC will accumulate in wine.

$\mathrm{EC}$, also known as urethane, is potentially toxic, and was re-classified in 2007 as probably human carcinogen compound (Group 2A) by the International Agency for Research on Cancer (IARC) [3,4]. This compound occurs in many fermented foods (e.g. yoghurt, bread) and alcoholic beverages (e.g. wine, beer, whiskey) $[3,5,6]$, being obtained from the reaction between ethanol and nitrogen-containing compounds (e.g. urea, citrulline, hydrogen cyanide, cyanogenic glycosides, and other $N$-carbamyl compounds), which has a moderate kinetic formation at room temperature. Nevertheless, not all nitrogen-containing compounds show the same kinetics when reacting with ethanol. For example, it has been demonstrated that EC formation from urea (which results from the degradation of arginine by yeasts) increases dramatically with temperature (for example in baking, boil- 
ing or toasting processes) $[3,6,7]$, and more rapidly than from citrulline [8].

The study of toxic and carcinogenic substances in foods represents one of the most demanding areas in food safety, due to their repercussions for public health. Apprehension related to EC occurrence in alcoholic beverages arose in 1985, when relatively high levels were detected by Canadian authorities in brandies and others liquors $[9,10]$. Consequently, maximum level of EC was firstly established by Canada authorities for alcoholic beverages, according to the consumption patterns and ADI (acceptable daily intake) value evaluation: $30 \mu \mathrm{g} / \mathrm{L}$ for table wine, $100 \mu \mathrm{g} / \mathrm{L}$ for fortified wines, $150 \mu \mathrm{g} / \mathrm{L}$ for distilled spirits, and $400 \mu \mathrm{g} / \mathrm{L}$ for fruit brandies and liquors $[11,12]$.

This regulation imposed by Canada to control the EC levels, appeared as a catalyst in the development of new methods. Several extraction methodologies have been used, such as continuous liquid-liquid extraction [13], and solid phase extraction $[7,14,15]$, combined with one-dimensional gas chromatography coupled with mass spectrometry detection (GC-MS). EC has been determined in fortified Madeira wines by SPE followed by GC-MS $[15,16]$, and by derivatization with 9 -xanthydrol, followed by high performance liquid chromatography (HPLC) [17]. More recently, a solvent-free methodology was used: solid phase microextraction (SPME) $[9,18,19]$. This methodology presents several advantages when compared with conventional solvent extraction procedures. SPME is rapid, easy to use, solvent-free, sensitive, and do not require any concentration step prior to analysis, preventing the production of artefacts [20]. The extraction step is followed mainly by GC-MS analysis $[7,13,15,16]$. To achieve the adequate sensitivity for EC detection, an injector equipped with a unit for large volume injection [7], or MS-SIM (selected ion monitoring) [13,19] or MS-MS acquisition modes (GC-MS-MS) $[9,14,21]$ were used. Onedimensional chromatographic processes are widely applied in the analysis of food products. In spite of the great separation power of conventional, one-dimensional modern chromatographic techniques, the accurate quantification of trace components requires a more sensitive methodology. Furthermore, deep analysis of the chromatograms frequently indicates that some peaks are the result of two or more co-eluting compounds. As a consequence of chromatographic co-elution, reliable MS identification and quantification is a very hard task [22], that can be overcome by tandem MS analysis [21]. Nevertheless, in the past years considerable research has been dedicated to the combination of independent methodologies with the aim of strengthening resolving power [23]. Comprehensive two-dimensional gas chromatography $(\mathrm{GC} \times \mathrm{GC})$ that employs two orthogonal mechanisms emerged as an interesting alternative to analyse complex samples or analyse trace target analytes within a single analysis. The method is based on the application of two GC columns coated with different stationary phases, such as one apolar and one polar, connected in series through a special interface (modulator). The composition of the stationary phase of the first dimension is generally less polar than the one used in the second dimension, so that the separation is ruled by boiling point properties in the first and polarity in the second one [24,25]. Therefore, two-dimensional gas chromatography $(\mathrm{GC} \times \mathrm{GC})$ offers faster run times, increased peak capacity, improved resolution and enhanced mass selectivity, good calibration linearity, more sensitivity and limits of detection are improved due to the focusing of the peak in the modulator when compared to the one-dimensional GC $[24,26,27]$.

Since the second column produces peaks as narrow as $0.1 \mathrm{~s}$, a detection technique must be fast enough to describe the peaks properly. This represents a problem for classical scanning mass spectrometers, which are capable of scanning rates up to 50 spectra/s. On the other hand, the high-speed time-of-flight mass spectrometry (ToFMS), with the maximum acquisition rates of 500 spectra/s, provides sufficient data density to address the requirements of GC $\times$ GC separations [22]. Besides that, ToFMS brings other advantages compared to tandem MS analysis such as full mass spectra acquisition at trace level sensitivity and mass spectral continuity, which allows for deconvolution of spectra of co-eluted peaks. As far as we know, the GC $\times$ GC-ToFMS has not been applied in the determination of ethyl carbamate, namely in alcoholic beverages. EC is present in trace amounts $(\mu \mathrm{g} / \mathrm{L})$, and the establishment of a suitable extraction procedure combined with an analytical methodology is an important challenge. Thus, the aim of this study is to develop a fast and simple methodology based on the headspace SPME (HS-SPME) combined with comprehensive GC $\times$ GC-ToFMS in order to quantify ethyl carbamate directly in the headspace of fortified wines. The performance of the methodology was evaluated in terms of linearity, limits of detection (LOD), limits of quantification (LOQ), precision and accuracy. Then, the methodology was applied to the analysis of 20 fortified Madeira wines including different types of wine obtained from several harvests in Madeira Island (Portugal).

\section{Materials and methods}

\subsection{Samples}

Twenty monovarietal fortified Madeira wines, including different types of wine (dry, medium dry, sweet and medium sweet fortified wines), obtained from several harvests (1990-2006) were analysed. These wines were produced from different Vitis vinifera L. varieties (Tinta Negra, Sercial, Verdelho, Malvazia and Bual varieties). The samples were kindly provided by Madeira Wine Company, the most representative producer of Madeira wine, Madeira Island (Portugal). The ethanol content of the Madeira wines under study ranged from $17 \%$ to $19 \%(\mathrm{v} / \mathrm{v})$.

\subsection{Reagents and standards}

Ethyl carbamate (99\%) was purchased from Sigma-Aldrich (Madrid, Spain). A stock solution with $3.80 \mathrm{mg} / \mathrm{L}$ of EC was prepared in ethanol (99.5\%, analytical grade, Panreac, Barcelone, Spain) and stored at $4{ }^{\circ} \mathrm{C}$. The standard solutions, used to prepare the calibration curve, were prepared by dilution of stock solution in ethanol. Glycerol (99.5\%) and glucose (99.5\%) were purchased from Sigma-Aldrich Química S.A. (Madrid, Spain). Tartaric acid (foodstuff grade) and sodium chloride (99.5\%, foodstuff grade) were provided by José M. Vaz Pereira (Lisboa, Portugal) and Sigma-Aldrich (Madrid, Spain), respectively. Ultra pure water was obtained from a Milli-Q system from Millipore (Milford, MA, USA).

\subsection{HS-SPME methodology}

The SPME coating fibre and the experimental parameters were adopted from a methodology previously developed in our laboratory for wine analysis [28]. As previous tests indicated the potential of this methodology to detected EC, this methodology was adopted to EC determinations. According to Lachenmeier et al. [9], CW/DVB fibre present high extraction efficiency for EC, as nowadays this fibre is not commercially available, a SPME fibre presenting a wide range of applications, including the EC, was selected. The SPME holder for manual sampling and fibre were purchased from Supelco (Aldrich, Bellefonte, PA, USA). The SPME device included a fused silica fibre coating partially cross-linked with 50/30 $\mu \mathrm{m}$ divinylbenzene-carboxen-poly(dimethylsiloxane) (DVB/CAR/PDMS). DVB/CAR/PDMS coating (molecular weight ranging from 40 to 275 ) combines the absorption properties of the liquid polymer with the adsorption properties of porous particles, which contains macro (>500 $)$, meso (20-500 $)$ and microporous 
(2-20 ̊) and has bipolar properties. The mutually synergetic effect of adsorption and absorption of the stationary phase promotes a high retention capacity and, consequently, a higher sensitivity than fibres based on absorption (PDMS and PA). The SPME fibre was conditioned at $270^{\circ} \mathrm{C}$ for $60 \mathrm{~min}$ in the GC injector, according to the manufacturer's recommendations. Then, the fibre was daily conditioned for $10 \mathrm{~min}$ at $250^{\circ} \mathrm{C}$.

For HS-SPME assay, aliquots of $1 \mathrm{~mL}$ of sample (Madeira wine and model wine) were placed into a $5 \mathrm{~mL}$ glass vial. After the addition of $0.5 \mathrm{~g}$ of $\mathrm{NaCl}$ and stirring $(0.5 \times 0.1 \mathrm{~mm}$ bar $)$ at $400 \mathrm{rpm}$, the vial was capped with a PTFE septum and an aluminium cap (Chromacol, Hertfordshire, UK). The vial was placed in a thermostatted bath adjusted to $60.0 \pm 0.1^{\circ} \mathrm{C}$ for $5 \mathrm{~min}$, and then the SPME fibre was inserted in the headspace for $20 \mathrm{~min}$. Each sample was analysed, at least, in triplicate. Blanks, corresponding to the analysis of the coating fibre not submitted to any extraction procedure, were run between sets of three analyses.

\subsection{GC $\times$ GC-ToFMS analysis}

After the extraction/concentration step, the SPME coating fibre was manually introduced into the GC $\times$ GC-ToFMS injection port at $250^{\circ} \mathrm{C}$ and kept for $3 \mathrm{~min}$ for desorption. The injection port was lined with a $0.75 \mathrm{~mm}$ I.D. splitless glass liner. Splitless injections were used (30 s). LECO Pegasus 4D (LECO, St. Joseph, MI, USA) GC $\times$ GC-ToFMS system consisted of an Agilent GC 6890N gas chromatograph, with a dual stage jet cryogenic modulator (licensed from Zoex) and a secondary oven. The detector was a high-speed ToF mass spectrometer. An HP-5 $30 \mathrm{~m} \times 0.32 \mathrm{~mm}$ I.D., $0.25 \mu \mathrm{m}$ film thickness (J\&W Scientific Inc., Folsom, CA, USA) was used as firstdimension column and a DB-FFAP $0.79 \mathrm{~m} \times 0.25 \mathrm{~mm}$ I.D., $0.25 \mu \mathrm{m}$ film thickness (J\&W Scientific Inc., Folsom, CA, USA) was used as a second-dimension column. The carrier gas was helium at a constant flow rate of $2.50 \mathrm{~mL} / \mathrm{min}$. The primary oven temperature was programmed from $40(1 \mathrm{~min})$ to $230^{\circ} \mathrm{C}(2 \mathrm{~min})$ at $10^{\circ} \mathrm{C} / \mathrm{min}$. The secondary oven temperature was programmed from 70 (1 min) to $250^{\circ} \mathrm{C}(3 \mathrm{~min})$ at $10^{\circ} \mathrm{C} / \mathrm{min}$. The MS transfer line temperature was $250^{\circ} \mathrm{C}$ and the MS source temperature was $250^{\circ} \mathrm{C}$. The modulation time was $6 \mathrm{~s}$; the modulator temperature was kept at $20^{\circ} \mathrm{C}$ offset (above primary oven). The ToFMS was operated at a spectrum storage rate of 125 spectra/s. The mass spectrometer was operated in the EI mode at $70 \mathrm{eV}$ using a range of $\mathrm{m} / \mathrm{z}$ $33-350$ and the voltage was $-1695 \mathrm{~V}$. Total ion chromatograms (TIC) were processed using the automated data processing software ChromaTOF (LECO) at $S / N$ threshold 10 . Contour plots were used to evaluate the separation general quality and for manual peak identification. A signal-to-noise threshold of 50 was used. Two commercial databases (Wiley 275 and US National Institute of Science and Technology (NIST) V. 2.0 - Mainlib and Replib) were used. A mass spectral match factor, similarity $>950$, was used to decide whether a peak was correctly identified or not. Furthermore, a manual inspection of the mass spectra was done, combined with the use of additional data, such as the retention index (RI) value. For the determination of the RI, a $C_{8}-C_{20} n$-alkanes series was used.

\subsection{Analytical plots}

For quantification purposes, two analytical plots were performed for EC using two matrices with different glucose contents, representing the different types of fortified Madeira wines: 56.51 and $87.63 \mathrm{~g} / \mathrm{L}$ for dry/medium dry and sweet/medium sweet fortified wines, respectively (Table 1 ). From the stock solution of EC $(3.80 \mathrm{mg} / \mathrm{L})$, ethanolic standard solutions were prepared with the following concentrations: 25.50, 51.06, 102.42, 408.14, 765.46,
Table 1

Validation parameters for ethyl carbamate in headspace of dry/medium dry and sweet/medium sweet wine model solutions using HS-SPME/GC $\times$ GC-ToFMS methodology.

\begin{tabular}{|c|c|c|}
\hline \multirow[t]{2}{*}{ Parameters } & \multicolumn{2}{|l|}{ Wine model } \\
\hline & Dry/medium dry & Sweet/medium sweet \\
\hline RI & \multicolumn{2}{|c|}{842} \\
\hline${ }^{1} t_{\mathrm{R}},{ }^{2} t_{\mathrm{R}}(\mathrm{s})$ & \multicolumn{2}{|c|}{$216,5.064$} \\
\hline Glucose (g/L) & 56.51 & 87.63 \\
\hline $\begin{array}{l}\text { Linear concentration } \\
\text { range }(\mu \mathrm{g} / \mathrm{L})\end{array}$ & $4.59-367.20$ & $8.89-547.20$ \\
\hline Calibration equation & $y=530.37 x+25917.08$ & $y=503.22 x+12540.14$ \\
\hline$r^{2}$ & 0.981 & 0.991 \\
\hline $\operatorname{LOD}(\mu \mathrm{g} / \mathrm{L})$ & 4.31 & 2.75 \\
\hline LOQ $(\mu \mathrm{g} / \mathrm{L})$ & 14.38 & 9.16 \\
\hline$\%$ recovery & $88.6(16)$ & $99.4(11)$ \\
\hline R.S.D. (\%) & 17.50 & 14.61 \\
\hline
\end{tabular}

RI, retention index obtained through the modulated chromatogram; $r^{2}$, correlation coefficients; LOD, limit of detection; LOQ, limit of quantification; R.S.D., repeatability, expressed as relative standard deviation (\%).

1326.08 and $2040.07 \mu \mathrm{g} / \mathrm{L}$ for dry/medium dry, and 49.40, 76.32, 152.29, 418.17, 874.05, 1520.16, $3040.45 \mu \mathrm{g} / \mathrm{L}$ for sweet/medium sweet model wines. Model wines (total volume of $1 \mathrm{~mL}$ ) with $18 \%$ $(\mathrm{v} / \mathrm{v})$, glycerol $(5.1 \mathrm{~g} / \mathrm{L})$, glucose $(56.51$ or $87.63 \mathrm{~g} / \mathrm{L})$, tartaric acid $(4.4 \mathrm{~g} / \mathrm{L})$, adjusted with $\mathrm{NaOH}$ at $\mathrm{pH} 3.5$, and fortified with $180 \mu \mathrm{L}$ of the EC ethanolic standard solutions previously described were prepared (see Table 1 for concentration range). Each one of these solutions were analysed by the HS-SPME/GC $\times$ GC-ToFMS methodology reported above (Sections 2.3 and 2.4).

Several analytical parameters of the proposed methodology were evaluated, such as linearity, limit of detection (LOD), limit of quantification (LOQ), precision (repeatability, expressed as relative standard deviation (R.S.D.)) and accuracy (recovery test). A minimum of seven concentration levels was used to build the analytical curve for both dry/medium dry and sweet/medium sweet wines. Linearity over the working range concentration was verified by regression analysis of total peak area $v s$ concentration. The LOD and LOQ were defined as the lowest EC concentration with estimated peak height greater than 3 and 10 times of the noise levels $(S / N>3$ and 10), respectively. All the experiments were performed at least in triplicate. For recovery assay, dry and sweet wines were spiked with EC $(97.14 \mu \mathrm{g} / \mathrm{L})$, and six replicates of the original and spiked wines were done and analysed by HS-SPME/GC $\times$ GC-ToFMS.

\section{Results and discussion}

\subsection{Quantification approach for assessment of ethyl carbamate}

Fig. 1 shows the GC $\times$ GC total ion current $(A)$ and extracted ion chromatogram contour plots of $\mathrm{m} / z 62$ (B) obtained from Madeira wine, showing the corresponding EC spot $\left({ }^{1} \mathrm{D} t_{\mathrm{R}}=216 \mathrm{~s}\right.$; ${ }^{2} \mathrm{D} t_{\mathrm{R}}=5.064 \mathrm{~s}$ ). The extracted ion chromatogram contour plot of $\mathrm{m} / \mathrm{z}$ 62 (Fig. 1B) illustrates a good chromatographic resolution, no interfering peaks from other fortified wine components, and adequate trace level sensitivity. To assure the adequate detection and quantification of the target analyte, some strategies should be proposed, namely the use of the ion extraction chromatography (IEC) mode that increases the specificity and sensitivity. IEC allows the analysis of a global volatile profile by combining the spectral evidence with a target ion selection and retention time, thus minimizing the contribution of co-eluted compounds and increasing the peak area of the targeted compound [29]. This approach was combined with the developed HS-SPME/GC $\times$ GC-ToFMS methodology, which guarantees peak purity and selectivity.

For quantification of EC in fortified wine, calibration plots were performed using the IEC mode $(m / z 62)$ for dry/medium dry and 

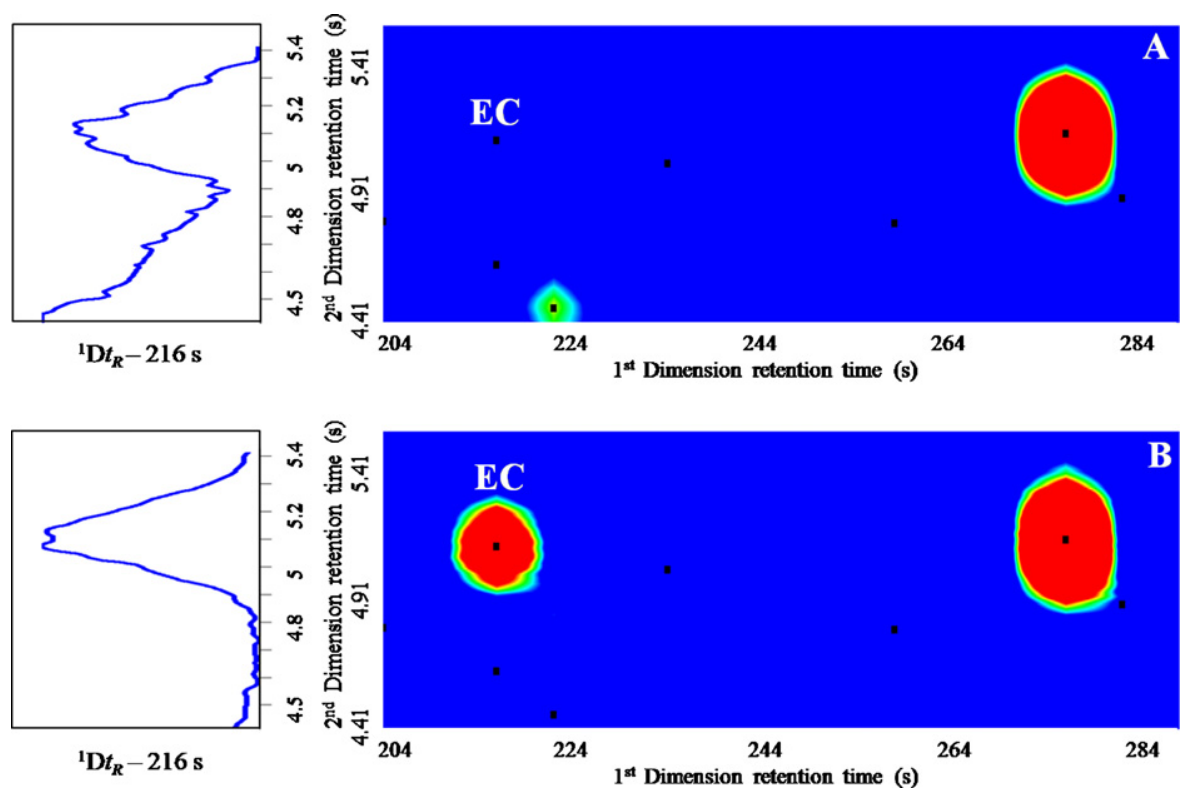

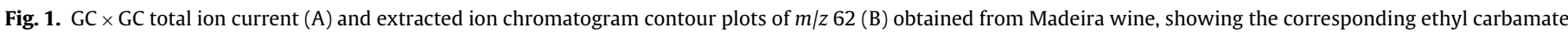
spot (EC). The black points correspond to the peak markers.

sweet/medium sweet model wines, and the results are reported in Table 1. Good regression coefficients $\left(r^{2}\right)$ were obtained for both analytical plots, 0.981 and 0.991 for dry/medium dry and sweet/medium sweet model wines, respectively. The limits of detection and quantification (LOD and LOQ) were calculated on the basis of the standard deviation of the replicate analyses concerning the EC standard with lowest concentration level, where LOD and LOQ are 3 and 10 times of standard deviation, respectively. Therefore, the LOD and LOQ were 4.31 and $14.38 \mu \mathrm{g} / \mathrm{L}$ for dry/medium dry model wines, whereas for sweet/medium sweet they were 2.75 and $9.16 \mu \mathrm{g} / \mathrm{L}$, respectively. A lower LOD and LOQ values were obtained for sweet/medium sweet wine model solutions. The higher glucose content in this type of wines comparative to dry ones can explain these results, as a higher glucose content promotes the decreasing of EC solubility in wine (ethanolic/aqueous matrix), consequently increases its releasing to the headspace [30]. The LOD and LOQ values, obtained for sweet/medium sweet model wines, were similar to those obtained by other authors employing HS-SPME/GC-MS$\operatorname{SIM}(3$ and $10 \mu \mathrm{g} / \mathrm{L}$ ) [19] to determine EC in beers, red wines, white wines, grape brandies and Chinese rice wines. On the other hand, considerable higher LOD and LOQ values (30 and $110 \mu \mathrm{g} / \mathrm{L}$ ) were obtained by Lachenmeier et al. [9] using HS-SPME/GC-MS-MS in stone-fruit spirits. These high values may be explained to the fact that stone-fruit spirits contain considerably higher levels of EC (in the $\mathrm{mg} / \mathrm{L}$ range) and also contain much higher levels of alcohol, which interfere with SPME extraction, so that the samples have to be diluted. Furthermore, lower LOD and LOQ values $(0.1$ and $1 \mu \mathrm{g} / \mathrm{L})$ were achieved by Jagerdeo et al. [7] to quantify EC table wines using SPE/LVI-MDGC-MS (solid phase extraction/large volume injectionmultidimensional gas chromatography-mass spectrometry). This MDGC-MS is composed by two gas chromatographs and a mass spectrometer that allowed heart-cutting peaks of interest and disposal of the unwanted portion of the chromatogram. The heartcutts of interest were then passed to the cryotrap and subsequently to the analytical GC for further separation and identification by the mass spectrometer. The previous selection of the heart-cutt of interest is a hard task, which is well addressed by the comprehensive two-dimensional GC $\times$ GC combined with ToFMS, where the global sample components were analysed and good resolution, mass selectivity, and sensitivity are achieved. Thus, it is important to point out that several methodological aspects are improved by the HS-SPME/GC $\times$ GC-ToFMS compared with previously reported bibliography, such as (i) reduction in extraction and in GC analysis times, and (ii) ToFMS full-scan acquisition mode allowed more complete data compared to MS-SIM, and MS-MS. By GC $\times$ GC-ToFMS, full-scan acquisition mode was used that allows to achieve simultaneously data about the global volatile profile of wine plus the EC target analyte. The MS-SIM and MS-MS acquisition mode only permit the specific analysis of a target analyte related to the $m / z$ selected ion.

In order to determine the accuracy of the analytical methodology, and to detect any matrix effect, the recovery efficiency was performed using the standard addition method, using dry and sweet Madeira wines. Both matrices were spiked with a known EC concentration $(97.14 \mu \mathrm{g} / \mathrm{L}$, final concentration of the wine $)$, and the recoveries were $88.6 \%$ and $99.4 \%$, for dry and sweet Madeira wines, respectively. Similar recoveries (92.8-94.3\%) were obtained by Zhang and Zhang [19]. Finally, the precision of the methodology was determined by performing six consecutive extractions of the lower EC concentration ( 4.59 and $8.89 \mu \mathrm{g} / \mathrm{L}$ ) in dry/medium dry and sweet/medium sweet model wines and the results, expressed as R.S.D., were $18 \%$ and $15 \%$, respectively. Higher R.S.D. values were obtained for dry/medium dry wine model solutions, which can be associated to the lower glucose content. According to Robinson et al. [30], a controlled increase in sugar content, improves the volatile compound in headspace partitioning without viscosity effect. Hence, a better linearity, recovery and precision were expected in sweet/medium sweet model wines comparatively to dry/medium dry model wines.

\subsection{Application to fortified wines}

The validated analytical methodology was applied to quantify EC in 20 fortified Madeira wines: five dry, four medium dry, six sweet, and five medium sweet wines (Table 2). The EC levels obtained for dry and medium dry Madeira wines range from 54.1 to $146.2 \mu \mathrm{g} / \mathrm{L}$, and for sweet and medium sweet wines from 64.2 to $162.5 \mu \mathrm{g} / \mathrm{L}$. EC levels, in $50 \%$ of the Madeira wines under study, exceeded the international limit established by Canada $(100 \mu \mathrm{g} / \mathrm{L})$, and other country that adopted this guidelines (Czech Republic). 
Table 2

Ethyl carbamate (EC) levels in fortified wines produced in Madeira Island.

\begin{tabular}{lllrr}
\hline Code & Type of wine & Year & EC $(\mu \mathrm{g} / \mathrm{L})$ & R.S.D. $(\%)$ \\
\hline A1 & Dry & 2006 & 86.2 & 17.84 \\
A2 & & 2004 & 66.6 & 12.52 \\
A3 & & 2004 & 141.5 & 3.41 \\
A4 & & 2001 & 146.2 & 13.03 \\
A5 & & 1999 & 125.8 & 14.58 \\
A6 & Medium dry & 2004 & 91.1 & 9.59 \\
A7 & & 2004 & 134.9 & 7.11 \\
A8 & & 2001 & 58.1 & 18.09 \\
A9 & & 1999 & 54.1 & 18.34 \\
A15 & Sweet & 2004 & 129.5 & 8.82 \\
A16 & & 1999 & 127.3 & 10.64 \\
A17 & & 1994 & 79.4 & 13.71 \\
A18 & & 1992 & 90.0 & 6.32 \\
A19 & & 2006 & 157.9 & 1.14 \\
A20 & & 2004 & 74.2 & 19.76 \\
A10 & Medium sweet & 83.6 & 8.58 \\
A11 & & 2004 & 108.2 & 8.27 \\
A12 & & 2004 & 64.2 & 12.38 \\
A13 & & 1999 & 8.89 \\
A14 & & 1993 & 162.5 & 11.42 \\
\hline
\end{tabular}

These results are similar with other studies [31,32] carried out on fortified wines, where $c a .50 \%$ of the wines under study exceeded the international limit $(100 \mu \mathrm{g} / \mathrm{L})$. The same authors also analysed several table wines, and EC levels were under the respective limit $(30 \mu \mathrm{g} / \mathrm{L})$. These results suggest that winemaking procedure may influence the EC formation.

On average, the higher concentration of EC was accounted for dry $(113.3 \mu \mathrm{g} / \mathrm{L})$, medium sweet $(110.9 \mu \mathrm{g} / \mathrm{L})$, and sweet fortified wines $(109.7 \mu \mathrm{g} / \mathrm{L})$, followed by medium dry $(84.6 \mu \mathrm{g} / \mathrm{L})$ fortified Madeira wines. No significant relation was achieved between the EC level and the age of the wine. Considering the Madeira wine processing, several parameters should be considered, namely baking process $\left(45-50^{\circ} \mathrm{C}\right)$, barrel aging and grape brandy addition. Nevertheless, others parameters which effect the EC formation from nitrogen-containing compounds could be considered, namely $\mathrm{pH}$, light, ethanol content, temperature, and concentration of catalytic metallic species ( $\mathrm{Cu}(\mathrm{II}), \mathrm{Fe}(\mathrm{III}))$ [3].

\section{Concluding remarks}

Comprehensive two-dimensional gas chromatography combined with solid phase microextraction (HS-SPME/GC $\times$ GC-ToFMS) is a potential useful tool for EC quantification directly in fortified wines that provides significant reduction in time of analysis compared to HPLC and one-dimensional GC methods. This methodology does not require a prior derivatization with 9-xanthydrol or any toxic solvent. The development of a methodology that allows the direct analysis of the sample without any previous handling is fundamental to avoid losses of analytes, and occurrence of artefacts. The use of GC $\times$ GC-ToFMS full-scan acquisition mode followed IEC mode allowed to achieve simultaneously quantification of EC target analyte, increasing specificity and sensitivity, and data about the global volatile profile of wine (in the present study, this data was not explored, but is available for future studies). The analytical methodology was validated using dry/medium dry and sweet/medium sweet wine models, and showed good results in terms of linearity, LOD, LOQ, precision and accuracy. It is important to point out that better performance was attainted with sweet model wine, as increasing of glucose content improves the volatile compound in headspace, and a better linearity, recovery and precision was achieved.

The proposed methodology was applied to analyse 20 fortified Madeira wines. In the wines under study, EC levels ranged from 54.1 (medium dry) to $162.5 \mu \mathrm{g} / \mathrm{L}$ (medium sweet). The results showed that $50 \%$ of the analysed Madeira wines exceeded the international limit established by Canada $(100 \mu \mathrm{g} / \mathrm{L})$ and other country that adopted these guidelines (Czech Republic). This data suggests the substantial role of the Madeira winemaking procedure on EC formation.

\section{Acknowledgements}

R. Perestrelo was supported by a Ph.D. grant from Fundação para a Ciência e Tecnologia (SFRH/BD/38855/2007). The authors thank the financial support of Research Unit 62/94, QOPNA, and Madeira Wine Company for kindly providing the samples used in this study.

\section{References}

[1] J.S. Câmara, M.A. Alves, J.C. Marques, Anal. Chim. Acta 555 (2006) 191.

[2] D.F. Stevens, C.S. Ough, Am. J. Enol. Viticult. 44 (1993) 309.

[3] J.V. Weber, V.I. Sharypov, Environ. Chem. Lett. 7 (2009) 233.

[4] D.W. Lachenmeier, F. Kanteres, T. Kuballa, M.G. López, J. Rehm, Int. J. Environ. Res. Public Health 6 (2009) 349.

[5] R.R. Madrera, B.S. Valles, Food Control 20 (2009) 139.

[6] I.C.C. Nóbrega, J.A.P. Pereira, J.E. Paiva, D.W. Lachenmeier, Food Chem. 117 (2009) 693.

[7] E. Jagerdeo, S. Dugar, G.D. Foster, H. Schenck, J. Agric. Food Chem. 50 (2002) 5797.

[8] S. Hasnip, A. Caputi, C. Crews, P. Brereton, Food Addit. Contam. A 21 (2004) 1155.

[9] D.W. Lachenmeier, U. Nerlich, T. Kuballa, J. Chromatogr. A 1108 (2006) 116.

[10] C.A. Uthurry, F. Varela, B. Colomo, J.A. Suárez Lepe, J. Lombardero, J.R.G. Hierro, Food Chem. 88 (2004) 329.

[11] S.M. Abreu, A. Alves, B. Oliveira, P. Herbert, Anal. Bioanal. Chem. 382 (2005) 498.

[12] S.N.F. Bruno, D.S. Vaitsman, C.N. Kunigami, M.G. Brasil, Food Chem. 104 (2007) 1345.

[13] C. Fauhl, R. Wittkowski, J. High Resolut. Chromatogr. Commun. 15 (1992) 203.

[14] W.C. Bumley, B.J. Canas, G.A. Perfetti, M.M. Mossoba, J.A. Sphon, P.E. Corneliussen, Anal. Chem. 60 (1988) 975.

[15] S. Hasnip, C. Crews, N. Potter, J. Christy, D. Chan, T. Bondu, W. Matthews, B. Walters, K. Patel, J. Agric. Food Chem. 55 (2007) 2755.

[16] M.A. Ferreira, J.O. Fernandes, Am. J. Enol. Viticult. 43 (1992) 339.

[17] P. Herbert, L. Santos, M. Bastos, P. Barros, A. Alves, J. Food Sci. 67 (2002) 1616.

[18] R.S. Whiton, B.W. Zoecklein, Am. J. Enol. Viticult. 53 (2002) 60.

[19] Y. Zhang, J. Zhang, Anal. Chim. Acta 627 (2008) 212.

[20] F.M. Musteata, J. Pawliszyn, TrAC Trends Anal. Chem. 26 (2007) 36.

[21] D.W. Lachenmeier, W. Frank, T. Kuballa, Rapid Commun. Mass Spectrom. 19 (2005) 108.

[22] S.M. Rocha, E. Coelho, J. Zrostlíková, I. Delgadillo, M.A. Coimbra, J. Chromatogr. A 1161 (2007) 292.

[23] P.Q. Tranchida, P. Dugo, G. Dugo, L. Mondello, J. Chromatogr. A 1054 (2004) 3.

[24] M. Herrero, E. Ibáñez, A. Cifuentes, J. Bernal, J. Chromatogr. A 1216 (2009) 7110.

[25] T. Górecki, O. Panić, N. Oldridge, J. Liq. Chromatogr. Relat. Technol. 29 (2006) 1077.

[26] J. Zrostlíková, J. Hajšlová, T. Čajka, J. Chromatogr. A 1019 (2003) 173.

[27] S.M. Song, P. Marriott, A. Kotsos, O.H. Drummer, P. Wynne, Forensic Sci. Int. 143 (2004) 87.

[28] R. Perestrelo, J.M.F. Nogueira, J.S. Câmara, Talanta 80 (2009) 622.

[29] E. Coelho, M.A. Coimbra, J.M.F. Nogueira, S.M. Rocha, Anal. Chim. Acta 635 (2009) 214.

[30] A.L. Robinson, S.E. Ebeler, H. Heymann, P.K. Boss, R.S. Solomon, R.D. Heymann, J. Agric. Food Chem. 57 (2009) 10313.

[31] B.S. Clegg, R. Frank, B.D. Ripley, N.D. Chapman, H.E. Braun, M. Sobolov, S.A. Wright, Environ. Contam. Toxicol. 41 (1988) 832.

[32] F. Funch, S. Lisbjerg, Lebensm. Unters. Forsch. 186 (1988) 29. 